\title{
PRESENTACIÓN I DE REFLEXIONES SOBRE POLÍTICA Y CULTURA EN LATINOAMÉRICA. MARCOS GARCÍA DE LA HUERTA, LECTURAS Y DESLECTURAS
}

\author{
Carlos Ossandón Buljevic \\ Universidad de Chile \\ cob2002@u.uchile.cl
}

“¿Cómo se hace un homenaje? ¿Cómo nos leemos? ¿Cómo hablamos de nosotros?”, se pregunta pertinentemente José Santos en el libro que ahora presentamos. "Estas preguntas - continúa- no son menores cuando no tenemos la costumbre siquiera de leer a nuestros autores, menos aún de comentarlos" (p. 23). A quemarropa, interrumpiendo el curso natural de las cosas, José Santos nos saca del embeleso, y nos confronta con una de las mayores incomodidades de la filosofía que se practica por estos lados del mundo. Se podría decir-precisamente- que es esa falta de costumbre nuestra de leernos o criticarnos la que, no solo nos deja sin la posibilidad de dialogar con distintas tradiciones de lectura, sino también consecuentemente de precisar unos lugares o modalidades de enunciación que puedan a su vez ser reconocidos por estas tradiciones. La afirmación de Humberto Giannini, y que Santos cita, es lapidaria en este sentido: "en Chile hay filósofos, pero no hay filosofía" (p. 22); contamos con filósofos individuales pero carecemos de una comunidad dialogante.

A las preguntas formuladas por José Santos, a propósito de su lectura de García de la Huerta, habría que agregar la dificultad adicional que presenta un texto que, como el que tenemos entre manos, se refiere a un autor que a su vez interviene, y con no poco protagonismo, en el propio desarrollo o modulaciones de este. ¿Cómo leer un texto con estas características? ¿Con qué ejemplos de la tradición podríamos contar? Independientemente de los hallazgos quizá puntuales que un acucioso investigador nos podría proporcionar, la verdad es que en lo fundamental la sensación es más bien de desamparo hermenéutico.

Sin embargo, este diagnóstico - difícil de contestar sobre todo en ciertas zonas de la filosofía- se puede matizar. La propia obra de Giannini es la expresión de la necesidad - practicada por él mismo de distintas maneras- de crear instancias de diálogo apostando a una "experiencia común" que ciertamente incluye la filosofía o que es más bien -subrayo- su condición de posibilidad. También José Santos en su comentario destaca el diálogo entre José Echeverría y Marcos García de la Huerta, así como en otros artículos ha examinado con detalle algunos de los encuentros que se han dado sobre todo entre aquellos que han buscado "dejar de ser extranjeros en /su/ propia tierra" (p. 35) o que han hecho del retorno al hogar un motivo para el filosofar. No es menor, por otra parte, el esfuerzo que viene haciendo Jorge Vergara, visible en el texto que nos ocupa y también en otros, por destacar investigaciones recientes de la filosofía en Chile, mostrando, y sobre todo fundamentando, la emergencia de una 
generación que él denomina "postmetafísica" en la que convergen distintas tradiciones críticas: la historia de las ideas, la epistemología más contemporánea, las elaboraciones actuales sobre cultura, arte y filosofía política. No podríamos dejar de mencionar en este rescate crítico el interés que ha venido enseñando Cecilia Sánchez en las operaciones o modalidades propias de la escritura filosófica, acercando la filosofía a la literatura y, por esta vía, arrojar una nueva mirada sobre unos textos cuyos análisis (con la excepción, por ejemplo, de Patricio Marchant) han atendido poco estos aspectos. Desde esta perspectiva, Cecilia Sánchez inscribe el pensamiento-escritura de García de la Huerta en la línea de la "ensayística latinoamericana moderna" (p. 83); modalidad abierta al diálogo con distintas disciplinas, alejada del "encierro intraacadémico" (p. 93), de las "grandes narraciones" (p. 83); y en la que la huella de los acontecimientos se expresa en lecturas filosóficas del presente.

Si aceptamos, por otra parte, desplazar el foco de atención, y nos dirigimos hacia registros más públicos que profesionales en el desarrollo del pensamiento, la constatación de múltiples intercambios, de lecturas y deslecturas, es aún más nítida. El propio García de la Huerta nos recuerda en su réplica a Carolina Pizarro -y es solo un ejemplo - la muy intensa polémica historiográfica, no exenta de consideraciones sobre filosofía de la historia, que comprometió a mediados del siglo XIX a Andrés Bello, José Victorino Lastarria y Jacinto Chacón. En la reconstitución de debates de gran importancia filosófica y pública, es muy relevante el aporte que ha hecho Carlos Ruiz Schneider en ámbitos diversos: el pensamiento conservador, las ideas y políticas educacionales, entre otros. Congruente con esta ampliación, Ruiz no deja de destacar en el libro que presentamos la interpretación crítica que hace García de la Huerta del texto "Nuestra América" de José Martí, problematizando las dimensiones identitarias actuantes en este célebre texto, cuestión que se une a la temática más general relativa a la tensión entre universalismo y particularismo.

No quisiera, sin embargo, pecar de optimista. Y esto a pesar de que no pocas investigaciones se realizan en la actualidad por jóvenes filósofos que, con viejos y nuevos pertrechos, desde las elaboraciones de Leopoldo Zea hasta otras más actuales provenientes de las distintas canteras críticas, ofrecen una pluralidad de entradas en la asunción reflexiva de un interés que está lejos de agotar su potencial en la mera constatación de empiricidades. Sin embargo, y a pesar de lo dicho, pienso que el diagnóstico de Santos es, en lo esencial, justo, marca una tendencia que suele ser predominante, y hace ostensible la enorme dificultad que tenemos de contar o mantener unas tradiciones de lecturas que pudiésemos negar, matizar, combinar o reafirmar.

De aquí la importancia del texto editado por Marcos Aguirre y Cecilia Sánchez. Desde un cierto ángulo - tal como lo detecta Jorge Vergara al comenzar su artículo-, los editores nos invitan a hacer un ejercicio que no es muy distinto del que regularmente hacen las tradiciones filosóficas europeas o norteamericanas que nos alimentan. Nos invitan a hacernos cargo críticamente de la obra de un autor, que como tal posee una trayectoria, un perfil singular o que solo a él pertenece, unas aperturas, y también o por lo mismo unos merecidos reconocimientos. Los editores al hacer justicia al autor Marcos García de la Huerta manifiestan a su vez una intención que se podría calificar de política, en la medida en que busca señalar un camino, entrar en la pelea por el 
sentido del quehacer filosófico, remediar en parte esa dificultad de construir o mantener tradiciones a la que me refería, mostrando un "sentido de ubicación" que es bastante raro entre los filósofos chilenos y que es ciertamente bastante menos excepcional en otras disciplinas de las humanidades o de las ciencias sociales.

Hay un par de rasgos de García de la Huerta que me interesaría destacar, que se desprenden del texto que nos ocupa. El primero tiene que ver con el rasgo ensayístico y crítico de su obra; una característica que lejos de ser adjetiva toca su "nervio". Se da aquí una rica confluencia - difícilmente distinguible- entre el "alma" y sus "formas", como diría Lukács, entre una subjetividad punzante, atrevida, inteligente y la dimensión argumentativa que la orienta. Esta combinación no está hecha para reconstruir con neutralidad "estados del arte", ni para exponer con palabras sencillas ideas complejas, ni para exhibir destrezas retóricas o estilísticas; tampoco para hacer inconfesables confesiones. Su norte es pensar el presente del mundo, azuzando para ello el diálogo y la argumentación razonada. Se trata, pues, de un discurso tan distante de la "mínima moralia" adorniana como de la aforística nietzscheana, que reconoce un lugar de enunciación y que no acepta sin más las pretensiones de una razón universal; un discurso que no se somete al reparto de competencias que suponen las tabiquerías establecidas entre las disciplinas, dado que lo que se sugiere son más bien conexiones, transversalidades, posibilidades, en suma, de abordajes indisciplinados. Lo que el autor llama "intra-historia", por ejemplo, representa un rescate de 'lo histórico' para la reflexión, una cuestión que se asocia directamente con la polémica antes mencionada -entre Bello, Chacón y Lastarria- sobre los modos de escribir la historia. Es pues en este escenario de conexiones diversas, donde el rasgo ensayístico y crítico de la obra de García de la Huerta se pone a prueba, tanteando, corrigiendo, afinando la puntería, reafirmando convicciones, sin ignorar -todo lo contrario- ni ciertos hitos de nuestra historia cultural ni tampoco acontecimientos decisivos para entender nuestro presente: la dictadura y la posdictadura.

En el esfuerzo por pensar el presente, García de la Huerta examina tópicos diversos, cuestión que los autores intervinientes en este homenaje hacen muy visible: la historiografía y sus relatos de nación en Carolina Pizarro; la cuestión de la razón tecnocrática en José Fernando García y Yuri Carvajal; la inevitable tarea de repensar la política en Marcos Aguirre, Cristina Hurtado, Mauricio Suárez y Tuillang Yuing, por citar ahora a los autores que, injustamente o por el curso que ha tomando este comentario, no he citado.

En medio de esta diversidad de tópicos y aperturas, sin olvidar los eventos que marcan nuestra evolución política, realizando una apropiación creativa de autores importantes, como Heidegger, Arendt o Foucault, el ensayismo de García de la Huerta tiene a la filosofía como eje articulador de su reflexión. El carácter articulador de la filosofía es precisamente lo que le faculta el acceso a unos límites, a unas fronteras o a unos sentidos que no son reductibles ni se confunden con las pesquisas propias de otras disciplinas. Es precisamente este registro el que nos permite apreciar cómo la obra de García de la Huerta, en el contexto más ancho de la filosofía en América Latina, viene -junto a otros autores que se pueden citar- a destrabar esa suerte de callejón sin salida que planteó, incluso más allá de sus propias intenciones, la etapa de la "normalidad 
filosófica" examinada y promovida hace ya tiempo por Francisco Romero. Para García de la Huerta, la especialización o el dominio del instrumental filosófico más exigente no se enemista ni excluye el reconocimiento de un lugar de pertenencia. Dicho desde otro ángulo, la "normalización" de su discurso no es incompatible con la tarea de repensar la política, en un tiempo caracterizado por la destrucción del mundo común, haciendo valer para ello condiciones o conflictos propios.

Quisiera terminar haciendo nuevamente alusión al texto-objeto que ocupa nuestra atención. Estoy pensando en unas exterioridades o superficies que también dicen o significan. Un texto donde García de la Huerta es tanto "objeto de estudio" como "sujeto de discurso" da cuenta de una propuesta editorial, de una modalidad que viene a revertir esa perturbadora mudez de la escritura señalada por Platón en el Fedro y recordada por Jacques Rancière en un texto reciente. Una modalidad que se corresponde perfectamente -si se me permite un lenguaje algo heracliteano- con ese "pólemos" que tan visiblemente constituye el "logos" de García de la Huerta. Me pregunto, entonces, si el presente libro no es desde esta perspectiva un aporte significativo no solo al conocimiento de un autor muy activo cuya obra se nutre de lecturas y réplicas, sino también a la necesidad de ir superando esa carencia de comunidad discutidora o interpeladora a la que aludimos al comienzo, ya que de ella depende-reitero-el propio destino de la filosofía. 